\title{
Erratum
}

\section{Neuroendocrine Control of Adrenocortical Ornithine Decarboxylase Activity}

G. Almazan, P. Pacheco, and T.L. Sourkes

Departments of Biochemistry and Psychiatry, McGill University, Montreal, Quebec, Canada

Exp Brain Res (1983) 50: 321-328

In the above mentioned article footnote a to Table 1 should read as follows: $\mathrm{pmol} \mathrm{CO}_{2}$ produced per mg protein per min during incubation of tissue for $45 \mathrm{~min}$ at $37^{\circ} \mathrm{C} \pm \mathrm{SEM}$. 